\title{
Correlation of the Rate of Solvolysis of 2-Chloro-thioacetophenones
}

\author{
Zoon Ha Ryu, ${ }^{\star}$ Song Hec Shin, Gui Tack Lim, ${ }^{\dagger}$ and Jong Pal Lee \\ Department of Chemistry, Dong-Eui University; Busan 614-714, Korea \\ ${ }^{\dagger}$ Department of Chemistry, Dong-A Unversity, Busan 604-7/4, Korea \\ Received Nonember 4. 2003
}

Key Words : Solvolyses, Grunwald-Winstein correlation parameters, 2-Chloro-thioacetophenones

According to the recent results of Kevill et al. ${ }^{1-3}$ from kinetic data for solvolyses, they reported that the introduction of S-atom adjacent to a reaction center caused a partial shilt away from the addition-climination $\left(\Lambda \mathrm{d}_{\mathrm{F}}\right)$ through dual reaction channel (DC) to the ionization channel (IC) for solvolysis of acid chloride [ic: $\operatorname{PhOCOCl}^{l}\left(\Lambda \mathrm{d}_{\mathrm{F}}\right) \rightarrow$ $\mathrm{PhSCOCl}^{1 \mathrm{~b} .2}=\mathrm{PhOCSCl}^{*}(\mathrm{DC}) \rightarrow \mathrm{PhSCSCl}^{3}(\mathrm{IC}) \mid$.

And more recent results of Ryu ef $a .^{+}$the results of the rates of solvolysis of $\alpha$-methylthioacetyl chloride (1) and phenylthioacetyl chloride (2) in more than 33 aqueous solvent system including 2.2.2-trifluoroethanol (TFE)-ethanol (EtOH) solvent can be explained by the same mechanism with the same structure of transition state (TS), controlled by the contribution from strong nucleophilic participation (third order reaction model for TFE-EtOH system) ${ }^{5}$ by the molecule of solvent as well as weakly solvent polarity (ionization). regardless of the different neighboring groups containing an S-atom [even if these are far away the reaction center, $(\mathrm{C}-\mathrm{O})]$

\section{Results and Discussion}

Accordingly, we have conducted the further research to investigate how S-methyl and S-phenyl groups influence the reaction center as well as the variation of reaction mechanism in solvolysis of 2-chloro-2-methylthioacetophenone $(3)^{6}$ and 2-chloro-2-phenylthioacetophenone $(4)^{7}$ (not acid chlorides), respectively at $25^{\circ} \mathrm{C}$ and $50^{\circ} \mathrm{C}$, for more than 40 solvent mixtures containing hexafluoro-iso-propanol (HFIP)water system and TFE-EtOH system (kinetic data in Table I<smiles>CSCC(=O)Cl</smiles>

1<smiles>CSC(Cl)C(=O)c1ccccc1</smiles>
3<smiles>O=C(Cl)CSc1ccccc1</smiles>

2<smiles>O=C(c1ccccc1)C(Cl)Sc1ccccc1</smiles>

4
Scheme 1

\footnotetext{
"Corresponding Author. e-mail: zhryu $($ deu.ac.kr
}

and 2), by using the same regression analysis such as those of corresponding 1 and 2 .

First of all. plot of $\log \left(k / k_{0}\right)$ for 3 at $25{ }^{\circ} \mathrm{C}$ ws. those of corresponding for 4 at $50^{\circ} \mathrm{C}$ (rate-rate profiles) in 43 solvents was observed as phenomenon of dispersion (correlation coefficient, $r^{-0.928)}$ due to the difference in solvation of the S-system between $\mathbf{3}$ and $\mathbf{4}$.

The reasonability of our interpretation for different solvation effects on the reaction site, with respect to the change in the position of an $\mathrm{S}$-atom from an $\mathrm{S}-\mathrm{CH}_{3}$ to $\mathrm{S}-\mathrm{Ph}$ group, can be confirmed by showing the a good linearity ( $\mathrm{c}-0.985$. slope -0.945$)^{4}$ in rate-rate profiles for solvolyses of 1 and those of $\mathbf{2}$ in the same solvent as these system.

Pure ethanol of the solvents investigated in our work has the highest probability of a bimolecular contribution $\left(\mathrm{Ad}_{\mathrm{F}}\right)$ to solvolyses, because of the relatively high nucleophilicity and (or) relatively low ionizing power. Conversely, pure water is a suitable as solvent for the ionization pathway, so

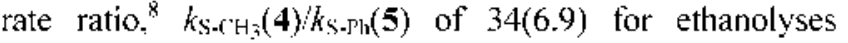
(hydrolysis) of 3 and 4 in pure ethanol (water) at $50^{\circ} \mathrm{C}$ (25 " $\mathrm{C}$ ), which should not be ignored even if small observed rate effects $(<100)$, ${ }^{1010}$ estimates that an $\mathrm{S}-\mathrm{CH}_{3}$ group attached reaction site is more favorable than an $\mathrm{S}-\mathrm{Ph}$ group, in regard to bimolecular pathway compared with ionization pathwaysolvolysis rate and $k_{\text {S-C } \mathrm{H}_{3}}(1) / k_{\mathrm{S}-\mathrm{Pl}}(2)-\mathrm{I} .0(2.7)$, being relatively much smaller values, for ethanolysis (hydrolysis) of $\mathbf{1}$ and $\mathbf{2}$ in $100 \%$ ethanol (water) at $10^{\circ} \mathrm{C}$ are obtained.

Consequently, we could not discover any evidence for the expected mesomeric interaction (1), which had been shown [by having a much higher rate ratio $(>1700)$ of $k_{\mathrm{N} . \mathrm{N}_{-1}\left(\mathrm{CH}_{3}\right)_{2}}$ ] $k_{\text {V.V.PH2 }}$ in pure water] for solvolysis rates of N,N-substituted carbamoyl chloride containing a carbamoyl group $(\mathrm{C}-\mathrm{O})$ as a reaction center studied by Kevill et $a l^{11}$ for solvolyses of 3 and 4.<smiles>[R]S[CH]C(=O)Oc1ccccc1</smiles>

Equation (1) indicates the efficient the stabilization of the developing mesomeric cation by the molecule of water as high polarity. 
Table 1. Rate constants $\left(k / \mathrm{s}^{-1}\right)$ for solvolyses of 3 in binary solvent mistures at $25^{\circ} \mathrm{C}^{\circ}$

\begin{tabular}{|c|c|c|c|}
\hline \multirow{2}{*}{$\begin{array}{l}\text { Solvent } \\
\text { Composi- } \\
\text { tion }^{b}\end{array}$} & \multicolumn{3}{|c|}{$\mathrm{k} / \mathrm{s}^{-1}$} \\
\hline & methanol-water & Ethanol-water & acetone-water \\
\hline 100 & $(1.08 \pm 0.05) \times 10^{-3}$ & $(1.70 \pm 0.10) \times 10^{-4}$ & - \\
\hline 90 & $(5.54 \pm 0.02) \times 10^{-3}$ & $(1.49 \pm 0.01) \times 10^{-3}$ & $(2.00 \pm 0.01) \times 10^{-5}$ \\
\hline 80 & $(8.09 \pm 0.04) \times 10^{-3}$ & $(2.67 \pm 0.03) \times 10^{-3}$ & $(2.00 \pm 0.01) \times 10^{-4}$ \\
\hline 70 & $(1.64 \pm 0.03) \times 10^{-\hat{-}}$ & $(5.71 \pm 0.01) \times 10^{-3}$ & $(7.95 \pm 0.15) \times 10^{-4}$ \\
\hline 60 & $(3.02 \pm 0.03) \times 10^{-\hat{\alpha}}$ & $(1.07 \pm 0.04) \times 10^{-2}$ & $(7.79 \pm 0.02) \times 10^{-3}$ \\
\hline 50 & $(6.53 \pm 0.02) \times 10^{-\hat{\alpha}}$ & $(2.03 \pm 0.06) \times 10^{-2 d}$ & $(9.02 \pm 0.17) \times 10^{-3}$ \\
\hline 40 & $(1.57 \pm 0.01) \times 10^{-1.7^{7}}$ & $(527 \pm 0.09) \times$ & $(2.96 \pm 0.1$ \\
\hline 30 & $(3.27 \pm 0$ & $(1.51 \pm 0.06) \times 10$ & $=0.02) \times 10^{-2}$ \\
\hline 20 & $(6.03 \pm 0$ & $(4.61 \pm 0.07) \times$ & $(2.62)$ \\
\hline 10 & $(9.55 \pm$ & $(6.81 \pm 0.00) \times 10^{-1 f}$ & $(8.17 \pm 0.01) \times 10^{-1 \epsilon}$ \\
\hline 0 & $(1.21 \pm 0.02) \times 10^{-1 f}$ & $(121 \pm 0.02) \times 10^{-1 f}$ & $(1.21 \pm 0.02) \times 10^{-1 /}$ \\
\hline & TFE-water & TFE-ethanol & HFIP-water ${ }^{c}$ \\
\hline 100 & $(1.18 \pm 0.01) \times 10^{-3}$ & $(1.18 \pm 0.01) \times 10^{-3}$ & - \\
\hline 97 & $(1.93 \pm 0.13) \times 10^{-38}$ & - & $(1.46 \pm 0.05) \times 10^{-2}$ \\
\hline 90 & $(5.35 \pm 0.04) \times 10^{-3}$ & - & $(1.35 \pm 0.01) \times 10^{-2}$ \\
\hline 80 & $(1.28 \pm 0.03) \times 10^{-\hat{-}}$ & $(1.69 \pm 0.03) \times 10^{-3}$ & - \\
\hline 70 & $(2.56 \pm 0.06) \times 10^{-\hat{-}}$ & - & $(3.43 \pm 0.09) \times 10^{-2}$ \\
\hline 60 & - & $(1.35 \pm 0.04) \times 10^{-3}$ & - \\
\hline 50 & $(5.14 \pm 0.01) \times 10^{-\hat{-}}$ & $(1.21 \pm 0.02) \times 10^{-3}$ & $(6.02 \pm 0.03) \times 10^{-2}$ \\
\hline 40 & - & $(1.02 \pm 0.03) \times 10^{-3}$ & - \\
\hline 20 & - & $(7.55 \pm 0.15) \times 10^{-4}$ & - \\
\hline
\end{tabular}

"Determined conductimeterically at least in duplicate tv pically injected a $\mu \mathrm{L}$ of $10^{\circ}$ or (wiw) substrate in dry acetonitrile into the kinetic apparatus. with a turbo-stirrer containing $2 \mathrm{~mL}$ of each solvent mixtures: errors shown are average deviations. "Solvent composition vi $\mathrm{v}^{0}$ iv by alcohol (trifluoroethanol). "Solvent composition wiv" by trifluoroethanol (water content were confimed as errors $\leq 0.3^{\circ}$, by using Karl Fisher Titrator). Injected $4 \mu \mathrm{L}$ of $5^{\circ} \mathrm{ow}(\mathrm{w} \mathrm{w})$ substrate in dry acetonitrile ${ }^{8}$ Injected $4 \mu \mathrm{L}$ of $3^{\circ}$ of (wiw) substrate in dry acetonitrile. Fnjected $4, t \mathrm{~L}$ of $1^{0}$ or(wiv) substrate in dry acetonitrile, ${ }^{g} \mathrm{~g}$ footnote of Table 1 in ref. $5 .{ }^{h} \mathrm{~g}$ footnote of Table 2 in ref. 5 .

Therefore. it means that the stabilization of TS for solvolyses of 3 and $\mathbf{4}$ are not affected by the mesomeric effect but by the solvation effect.

An evaluation of rates of solvolysis of 3 and 4 were also carried out in terms of the Grunwald-Winstein type equation ${ }^{1: .13}$ with ionizing power parameter $\left(\mathrm{Y}_{\mathrm{C}}\right.$ : based on the solvolyses of 1-adamantyl chloride. $m=1.00)^{13}$ as shown in Table 3 .

$$
\log \left(k / k_{\mathrm{c}}\right)=\mathrm{mY}+\mathrm{c}
$$

In equation (2). $k$ and $k_{0}$ refer to the specific rates of solvolysis in a given solvent and in $80(\mathrm{v} / \mathrm{v}) \%$ aqueous ethanol. respectively: $\mathrm{m}$ is the susceptibility to change in ionizing power $\left(\mathrm{Y}_{\mathrm{Cl}}\right)$ and $\mathrm{c}$ is the intercept (residual term) and then these results. including dispersion patterns $(r=$ $0.838-0.890)$ for plots of single parameter $\left(\mathrm{Y}_{\mathrm{Cl}}\right)$. were summarized in Table 3 .

Such phenomena of dispersion were further analyzed using dual Gnunwald-Winstein correlation [equation (3)]. considering solvent nucleophilicity terms. $/ \mathrm{N}_{\mathrm{T}}\left(\mathrm{N}_{\mathrm{T}}\right.$ : base on the solvolyses of S-methyl dibenzothiophenium ion. ${ }^{14} I$ : the susceptibility to change in solvent nucleophilicity. $\mathrm{N}_{\mathrm{T}}$ ) from equation (1)
Table 2. Rate constants $\left(h / \mathrm{s}^{-1}\right)$ for solvolyses of 5 in binary solvent mixtures at $50^{\circ} \mathrm{C}^{a}$

\begin{tabular}{|c|c|c|c|}
\hline \multirow{2}{*}{$\begin{array}{c}\text { Solvent } \\
\text { Composi- } \\
\text { tion }^{b}\end{array}$} & \multicolumn{3}{|c|}{$h / \mathrm{s}^{-1}$} \\
\hline & methanol-water & ethanol-water & acetone-water \\
\hline 100 & $(4.65 \pm 0.05) \times 10^{-4}$ & $(1.25 \pm 0.15) \times 10^{-1}$ & \\
\hline 90 & $(1.04 \pm 0.03) \times 10^{-3}$ & $(2.15 \pm 0.15) \times 10^{-1}$ & \\
\hline 80 & $(2.81 \pm 0.04) \times 10^{-3}$ & $(4.00 \pm 0.00) \times 10^{-4}$ & \\
\hline 70 & $(4.97 \pm 0.14) \times 10^{-3}$ & $(8.05 \pm 0.05) \times 10^{-4}$ & $(7,00 \pm 0,00) \times 10^{-5}$ \\
\hline 60 & $(6.28 \pm 0.01) \times 10^{-3}$ & $(1.37 \pm 0.03) \times 10^{-3}$ & $(2.30 \pm 0.30) \times 10^{-4}$ \\
\hline 50 & $(1.57 \pm 0.08) \times 10^{-2 A}$ & $(3.94 \pm 0.03) \times 10^{-3}$ & $(9.25 \pm 0,05) \times 10^{-4}$ \\
\hline 40 & $(2.04 \pm 0.06) \times 10^{-2 A}$ & $(7.18 \pm 0.05) \times 10^{-3}$ & $(2.97 \pm 003) \times 10^{-3}$ \\
\hline 30 & $(4.50 \pm 0.09) \times 10^{-1}$ & $(2.03 \pm 0.14) \times 10^{-32 t}$ & $(6.41 \pm 0,09) \times 10^{-k}$ \\
\hline 20 & $(1.07 \pm 0.03) \times 10^{-1}$ & $(7.72 \pm 0.05) \times 10^{-3 t}$ & $(3.71 \pm 0.01) \times 10^{-3 x}$ \\
\hline 10 & $(1.72 \pm 0.04) \times 10^{-1 /}$ & $(1.83 \pm 0.01) \times 10^{-l e}$ & $(1.35 \pm 0.05) \times 10^{-1 e}$ \\
\hline 0 & $\left(3.74 \pm 0 .(2) \times 10^{-1 /}\right.$ & $\left(3.74 \pm 0 .(02) \times 10^{-1 /}\right.$ & $(3.74 \pm 002) \times 10^{-1 / f}$ \\
\hline & TFE-water & TFE-othanol & HFIP-water \\
\hline 100 & $(1.68 \pm 0.03) \times 10^{-3}$ & $(1.68 \pm 0.03) \times 10^{-3}$ & - \\
\hline 97 & $(1.35 \pm 0.04) \times 10^{-3}$ & - & $(1.28 \pm 0,00) \times 10^{-2}$ \\
\hline 90 & $(2.76 \pm 0.05) \times 10^{-3}$ & - & $(1.33 \pm 009) \times 10^{-2}$ \\
\hline 80 & $(4.82 \pm 0.02) \times 10^{-3}$ & $(7.60 \pm 0.20) \times 10^{-4}$ & - \\
\hline 70 & $(7.93 \pm 0.30) \times 10^{-3}$ & - & $(1.62 \pm 0.10) \times 10^{-2}$ \\
\hline 60 & - & $(5.75 \pm 0.15) \times 10^{-4}$ & - \\
\hline 50 & $(1.43 \pm 0.07) \times 10^{-1}$ & $(4.20 \pm 0.10) \times 10^{-4}$ & $(205 \pm 001) \times 10^{-2}$ \\
\hline 40 & - & $(3.33 \pm 0.15) \times 10^{-4}$ & - \\
\hline 20 & - & $(1.65 \pm 0.05) \times 10^{-4}$ & - \\
\hline
\end{tabular}

-Determined as described footnote a in table 1 .

$$
\log \left(k / k_{0}\right)=/ \mathrm{N}_{\mathrm{T}}+\mathrm{mI}_{\mathrm{Cl}}+\mathrm{c}
$$

According to the previous results ${ }^{+}$reported for solvolyses of 1 and 2. these are very similar m-values $(0.39-0.45)$ and $l$-values $(1.02)$ with $\mathrm{r}$ to be acceptable value $(\mathrm{r} \approx 0.963)$, when used dual regression analysis. as the linear correlation for 33-35 aqueous solvent systems including TFE-EtOH solvent system.

For solvolysis of 3 with $\mathrm{S}-\mathrm{CH}_{3}$ group. as exhibited in Figure 1, the observation of one good linear dual GrunwaldWinstein plot (equation 3). over the full range of the 38

Table 3. Conelation analyses of $\log \left(k k_{1}\right)$ for solvolyses of various compound studied with single or dual parameter Grunwald-

\begin{tabular}{|c|c|c|c|c|c|c|c|}
\hline \multicolumn{2}{|c|}{ Compound Parameter } & $\mathbf{n}^{b}$ & $r$ & $\overline{m^{\prime \prime}}$ & d & $\mathrm{h}^{\prime \prime}$ & $\mathrm{c}^{\mathrm{s}}$ \\
\hline \multirow[t]{4}{*}{$3\left(25^{\circ} \mathrm{C}\right)$} & $\mathrm{Y}_{\mathrm{Cl}}$ & 39 & 0.884 & 0.52 & & & -0.245 \\
\hline & & 43 & 0.838 & 0.46 & & & -0.215 \\
\hline & $\mathrm{Y}_{\mathrm{Cl}}, \mathrm{N}_{\mathrm{T}}$ & 38 & 0.980 & 0.71 & 0.66 & & 0.029 \\
\hline & & 43 & 0.979 & 0.70 & 0.60 & & 0.001 \\
\hline \multirow[t]{5}{*}{$+\left(50^{\circ} \mathrm{C}\right)$} & $Y_{\mathrm{Cl}}$ & $388^{\prime}$ & 0.890 & 0.47 & & & 0.045 \\
\hline & & 42 & 0.877 & 0.44 & & & 0070 \\
\hline & $\mathrm{Y}_{\mathrm{Cl}}, \mathrm{N}_{\mathrm{T}}$ & $388^{r}$ & 0.931 & 0.59 & 0.37 & & 0.176 \\
\hline & & 41 & 0.932 & 0.58 & 0.33 & & 0.159 \\
\hline & $\mathrm{Y}_{\odot \mathrm{l},}, \mathrm{N}_{\tau, \mathrm{I}}$ & 27 & 0.936 & 0.63 & 0.47 & 0.66 & 0.130 \\
\hline
\end{tabular}
Winstein equation [(2), (3) and $(4)]^{a}$

Origin 6.0 program were used to for the multiple regression analysis. 'Number of solvents. "Correlation coefticient. "Sensitivity to each solvent parameter chosen. "Constant value obtained from correlation. 'Except for hexafluoro-iso-propanol sustems. 


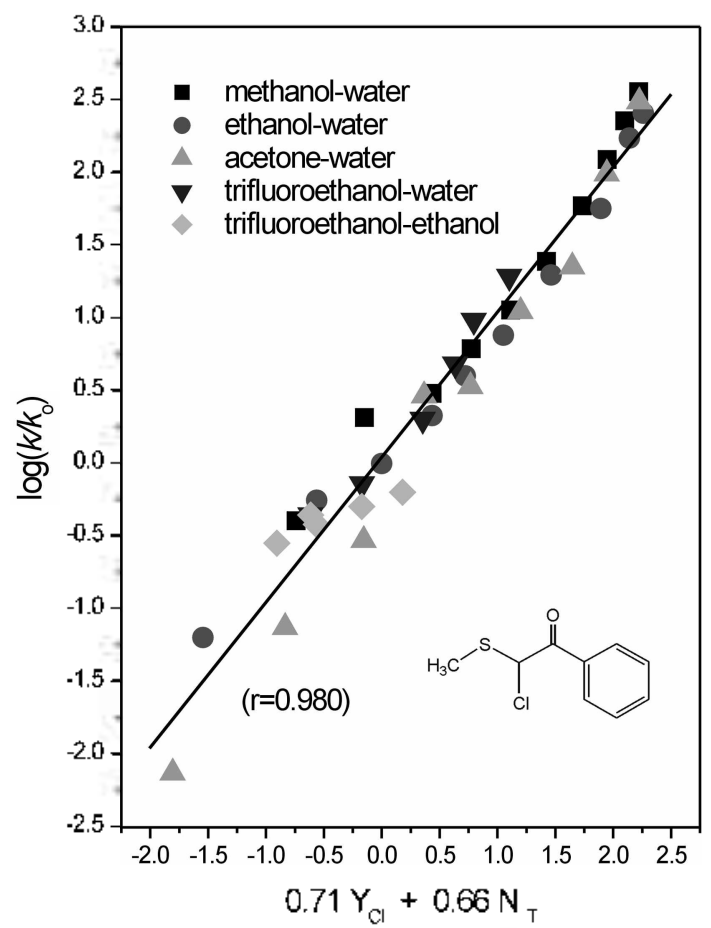

Figure 1. Correlation of logarithms of rate for solvolyses of 3 in various solvent system at $25^{\circ} \mathrm{C}$.

solvents chosen, with $l=0.66$ and $\mathrm{m}=0.71$ values $(\mathrm{r}=$ 0.980 ) suggests that these solvolysis rates of 3 depend on two solvation parameters $\left(\mathrm{Y}_{\mathrm{C},}, \mathrm{N}_{\mathrm{J}}\right)$ and imply a unity of mechanisın, involving solvent nucleophilic participation by solvent molecule from the rear side in T'S of ionization (as expected for $\mathrm{S}_{2} 2$ reaction of $\alpha$-haloketones). ${ }^{15}$

In the case of solvolysis of 4 with $\mathrm{S}-\mathrm{l}$ h group, analysis of the rates of solvolysis, using the identical set of solvents and solvent parameters |equation (3)| as used in 3 , obtained unsatisfactory results with $\mathrm{r}=0.931(\mathrm{~m}=0.59, l=0.37)$ as a linear correlation and manifested the same results such as above (no change in r-values) when performed 41 solvents including HFIP-water system and the application of multiple Grunwald-Winstein parameter involving the aromatic ring parameter (I) ${ }^{\mid t ;}$ proposed by Kevill was performed,

$$
\begin{aligned}
\log \left(k / k_{0}\right)= & l \mathrm{~N}_{\mathrm{T}}+\mathrm{mY}_{\mathrm{cl}}+\mathrm{hI}+\mathrm{c} \\
& \text { (h: susceptibility to I parameter) }
\end{aligned}
$$

Our results analyzed so far are listed in table 3 and c-value corresponding residual term of equation (3) for 1, 2 and 3 were observed to be very small $(c--0.016-0.032)^{+}$except for 4 with the relatively large value of $c-0.176$. These mean that the rates of solvolysis of 1,2 and 3 for all solvent systems chosen in this work can be evaluated by dual parameter correlation analyses (equation 2), but are different from that of 4.

Solvolysis rates of 4 at $50^{\circ} \mathrm{C}$ exhibits a nicely linear relation $(\mathrm{r}-0.991)$ with $\mathrm{Y}_{\mathrm{Cl}}$ for 15 solvents in Figure 2 , being more than 2.85 of corresponding $\mathrm{Y}_{{ }_{\mathrm{l}} \mathrm{l}}$ value of $97 \%$ (w/w) TFE-water system, and obtain the m-value of corresponding slope -1.24 to be considered to proceed by limiting mechanism $(m-1.00$ for $\mathrm{l}$-adamantyl chloride established as $\mathrm{S}_{x} \mathrm{~L}$-standard compound)..$^{13}$

Positive activation entropy $\left(\Delta S^{\dot{*}}=9.17 \mathrm{cal} \mathrm{mol}^{-1}\right)^{1 ?}$ provide additional support for the validity of $\mathrm{S}_{\mathrm{V}} \mathrm{I}$ mechanism in high polar solvent systems.

Consequently, in Figure 2, the solvent systems deviated from the corresponding correlation line of the rationalization as favoring the ionization channel, leading to carbocationic intermediates, can be responsible for favoring a bimolecular the reaction channel and the different slopes of the dotted lines to each solvent system may reflect the degree of the nucleophilic solvation at the reaction site. Solvent composition of pure ethanol lies on the straight dotted line for methanol-water solvent system, this may be another expression for the predominance of ethanol as a nucleophilic solvent in this solvolysis.

Finally, kinetic solvent isotope effect (KSIE) have been performed satisfactorily as an additional tool for mechanistic identification in solvolyses under favor of the values of solvolysis rate ratio $40 \%(\mathrm{v} / \mathrm{v})$ ethanol-water and $97 \%(\mathrm{w} / \mathrm{w})$ [FE-water solvent system $\left[k_{101} i k_{97}\right]$ ) so that these values observed and the additional kinetic data were ascribed together in lable 4 . For $\mathbf{1}^{4}$ and $\mathbf{2}^{4}$, the values $(\geq 1.49)$ for KSIE are within the range predicted for the bimolecular solvolysis which is accompanied by general base catalysis and $\left.\left[k_{101} / k_{i>r_{1}}\right]\right]$ values of $<215-254$ are also within the range of favoring mucleophilic solvation, even if these values are less than 500 of corresponding methyl tosylate (MeO's) ${ }^{18}$ at $25^{\circ} \mathrm{C}$ known as model compound for the bimolecular reaction. These results $(l=1.02-1.03)^{4}$ are closely consistent with those previously analyzed in terms of dual GrunwaldWinstein parameters [equation (2)].

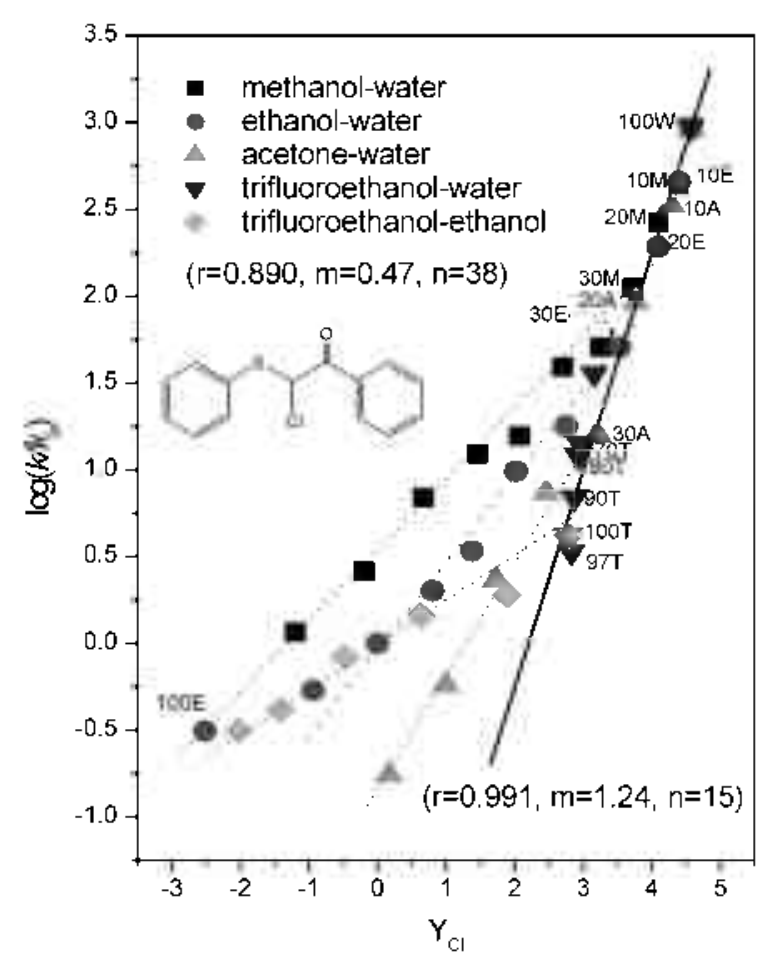

Figure 2. Correlation of logarithms of rate constants for solvolyses of 5 with $\mathrm{Y}_{\mathrm{Cl}}$. 
Table 4. Rate constants $\left(\mathrm{s}^{-1}\right.$ ) in methanol kinetic solvent isotope effect (KSIE) and values of solvolvses rate ratio in $40(\mathrm{v} / \mathrm{v}) \%$ ethanol/water compared with $97(\mathrm{w} / \mathrm{w}) \%$ trifluoroethanol/water for 3 and $4^{7}$

\begin{tabular}{ccccc}
\hline Compound & $\mathrm{MeOH}$ & $\mathrm{MeOD}^{b}$ & $\left(k_{\mathrm{H}} / k_{\mathrm{D}}\right)^{r}$ & {$\left[k_{4(\mathrm{E}} / k_{y: \mathrm{T}}\right] \mathrm{Y}^{\gamma^{\gamma}}$} \\
\hline $3\left(25^{\circ} \mathrm{C}\right)$ & $(1.08 \pm 0.05) \times 10^{-3}$ & $(1.05 \pm 0.10) \times 10^{-3}$ & 1.03 & 27 \\
$5\left(50^{\circ} \mathrm{C}\right)$ & $(4.65 \pm 0.05) \times 10^{-4}$ & $(3.85 \pm 0.25) \times 10^{-1}$ & 1.21 & 5.3 \\
\hline
\end{tabular}

"Deternined conductimetrically at least in duplicate. "MeOD was Aldrich $\% 99.5^{\circ}{ }^{\circ}=$ D). "Kinetic solvent isotope effect. "Subscribed Y symbol means

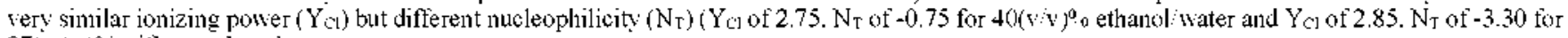
$97($ wiw) 0 trifluoroethanoliwater.

In contrast. snall values of KSIE for $3(1.03)$ and for $4(1.21)$ are very similar to those reported for MeOTs $(1.11)^{19}$ at $49.8^{\circ} \mathrm{C}$ and in case of $\left[k_{4(\mathrm{E} E} / k_{97 \mathrm{~T}}\right]$ Y values for 3 and 4 , the value of 5.3 for 3 is analogous to that of 4.7 for 2 -naphthoyl chloride ${ }^{2 i j}$ estimated as a dual reaction mechanism and those for 3 (27) show higher than those of 4 , but smaller that these for 1 and 2.

\section{Conclusions}

Our research have conducted to obtain further information on the possible effect of adjacent group including S-atom to reaction center [ie: $\mathrm{S}-\mathrm{CH}_{\hat{j}}$ or $\mathrm{S}-\mathrm{Ph}$ group]. Consequently, the change from a unit of mechanism indicating $\mathrm{S}_{* 2}$ type [S$\mathrm{CH}_{3}$ (3)]. involving solvent nucleophilic participation by a molecule of the solvent from the rear side in TS of ionization. to the dual reaction chanuel $[\mathrm{S}-\mathrm{Ph}(4)]$ with $\mathrm{S}_{\mathrm{K}} \mathrm{l}$ $\mathrm{S}: 2$ type by means of a specific solvent effect has shown in solvolyses of 2-chloro-2-thioacetophenone ( 3 and 4 ). Such phenomenon can be explained as a difference in the solvation between $\mathrm{CH}_{3}$ - and $\mathrm{Ph}$-group, considering previous the result ${ }^{\hat{1}}$ reported as a quite different solvation between alkyl groups $\left(\mathrm{CH}_{3}-\right)$ and aromatic rings (Ph-) in solvolyses of substituted acetyl chloride in fluorinated alcohol systenis.

\section{Experimental Section}

Materials. 2-Chloro-2-methylthioacetophenone $(3)^{6}$ was prepared from the reaction of $\alpha$-(methylthio)acetophenone (4.5 g. $0.027 \mathrm{~mole}$ ) in $40 \mathrm{~mL}$ of carbon tetrachloride $\left(\mathrm{CCl}_{4}\right)$ with N-chlorosuccinimide (NCS: $3.61 \mathrm{~g} .0 .027 \mathrm{~mole}$ ) at room temperature during 6 hours and then the product was purified by distillation under reduced pressure (b.p: $135^{\circ} \mathrm{C} / 6$ $\mathrm{mmHg}$ ) after filtering the residue (succinimide) [analytical data obtained: oil phase. ${ }^{1} \mathrm{H}-\mathrm{NMR}\left(\mathrm{CDCl}_{3}\right) \delta: 2.24$ (3H. s. $\left.\left.\mathrm{SCH}_{3}\right), 6.34(1 \mathrm{H} . \mathrm{s} . \mathrm{CH}), 7.46-8.08(5 \mathrm{H}, \mathrm{m} . \mathrm{ArH})\right] .2-$ Chloro-2-phenylthioacetophenone $(4)^{7}$ was also prepared from the reaction of $\alpha$-(phenylthio)acetophenone ( 6 g. 0.026 mole) in $\mathrm{CCl}_{4}(40 \mathrm{~mL})$ with NCS $(3.47 \mathrm{~g} .0 .026$ mole) and then the residue was purified by column chromatography $\left(\mathrm{SiO}_{2} . \mathrm{C}_{6} \mathrm{H}_{6}\right)$ by the same method as ref. 6 [analytical data obtained: oil phase. ${ }^{1} \mathrm{H}-\mathrm{NMR}\left(\mathrm{CDCl}_{3}\right) \delta .6 .41(1 \mathrm{H} . \mathrm{s} . \mathrm{CH})$. $7.21-8.10(10 \mathrm{H}, \mathrm{m} . \mathrm{ArH})]$. All solvents used for kinetics in this work were dried and distilled by standard methods.

Kinetic methods. The rate constants for solvoly tic reaction proceed as pseudo-first type were determined using a general conductimetric method ${ }^{5}$ and calculation of those were performed by the Origin 6.0 program using the Guggenheim equation ${ }^{2}$ from data monitored automatically.

Acknowledgement. We are grateful to T. W. Bentley and D. N. Kevill for helpful comments.

\section{References}

1. (a) Kevill. D. N.: D'Souza, M. J. J. Chem. Soc. Perkin Trans. 2 1997. 1271. (b) Queen. A. Can. J. Chem. 1967. 45.1619.

2. Kevill. D. N.: Bond. M. W. D'Souza. M. T. J. Org Chem. 1997. 62.7869 .

3. Kevill. D. N.: D'Souza M. J. Can. J. Chem. 1999,77. 1118.

4. Ryu. Z. H.; Shin, S. H.: Lee. J. P.: Lim, G. T: Bentlev, T. W. $J$. Chem. Soc. Pohin Trans. 2 2002. 1283.

5. Ryu. Z. H.: Lim. G. T.: Bentley. T. W. Bull. Korem Chem. Soc. 2003. 9.1293

6. Prepared by synthesis method proposed literature (Choi. H. D.: Seo. P. J.; Son. B. W. J. Korean Chem. Soc. 1999. 13, 494).

7. Prepared by the same method as ref. 6 .

8. Obtained from rate constant $k \mathrm{~s}-\mathrm{CH}_{3}(3)=(4.25 \pm 0.03) \times 10^{-3} \mathrm{~s}^{-1}$ for the corresponding hydrolysis of 4 at $25^{\circ} \mathrm{C}$.

9. Polla. E.: Boreic. S.: Sunko. D. E. Tetrahedron Leth. 1975. 799.

10. Mihel. I.: Orlovic. M.: Polla. E.: Boreic. S. J. Ong. Chent. 1979. H. 4086 .

11. D'Souza. M. J.: Keivill. D. N. J. Org Chem. $1995,60,1632$

12. Grunwald, E.: Winstein. S. J. Am. Chem. Soc. 1948, 70. 846.

13. Bentley. I. W.: Llewellyn. G. Prog. Phus. Org. Chem. 1990. 17. 121 .

14. (a) Kevill. D. N.: Anderson. S. W. J. Org Chent 1991. 56.1845. (b) Kevill, D. N.; D'Souza, M. J. J. Chent. Res. (S) 1993. 174. (c) Kevill. D. N. In Advances in Quantitative Stucture Products Relationships: Charton, M.. Ed, JAI Press: Greenwich, CT. 1996: Vol. I.p 81 .

15. March. J. Achanced Organic Chemismy 3rd ed: 1985: $\mathrm{p} 302$.

16. Kevill. D. N.: D'Souza. M. T. J. Cheni Soc. Perkin Trans. 21995. 973 .

17. Obtained from the Erying plot using rate constants $k_{15}{ }^{\circ} \mathrm{C}=1.76 \times$ $10^{-2} \mathrm{~s}^{-1}, k_{3} \mathrm{O}_{\mathrm{O}}=3.39 \times 10^{-2} \mathrm{~s}^{-1}, k_{10} 0^{\circ} \mathrm{C}=1.07 \times 10^{-1} \mathrm{~s}^{-1}$ and $k \mathrm{~s}_{10} \mathrm{CO}^{\circ}=$ $\left.3.74 \times 10^{-1} \mathrm{~s}^{-1}\right)$ for hydrolysis of 4 in pure water.

18. Raber. W. C.: Neal. Tr.: Dukes. M. D.: Harris. I. M.: Mount. J. $J$. An Chem. Soc. 1978.8137.

19. Bentley. T. W.; Llewellyn. G.; Rvu, Z. H. J. Org. Chen. 1998. 63. 4654.

20. Ryu. Z. H.: Ju. C.-K.; Sung. D. D.; Sung. N. C.: Bentlev: T. W. Bull. Korean Chem. Soc. 2002. 23.123.

21. Oh. O. H.: Jang. G. G.: Lim. G. T.: Ryu. Z. H. Bull. Korem Chent Soc. 2002. 23. 1089 .

22. Guggenheim. E. A. Philos. Mag. 1926. 2.538 